\title{
DISCUSSION
}

\section{Rigorous plasticity solutions for the bearing capacity of two-layered clays}

\author{
R. S. MERIFIELD, S. W. SLOAN and H. S. YU (1999). Géotechnique 49, No. 4, 471-490
}

\section{M. Goss and D. V. Griffiths, Colorado School of Mines}

The authors have very effectively presented upper and lower bound plasticity solutions for the classical problem of the bearing capacity of two-layered clays.

In referring to alternative methods of solving this problem however, the authors state the 'experience has indicated that results from the displacement finite element method tend to overestimate the true limit load and, in some instances, fail to provide a clear indication of collapse altogether'.

This is not the experience of others working in the field, who know that the locking phenomenon to which the authors refer is easily avoided. The elasto-plastic displacement finite element method has been shown repeatedly (e.g. Zienkiewicz et al., 1975; Griffiths, 1982; Griffiths \& Lane, 1999) to give reliable

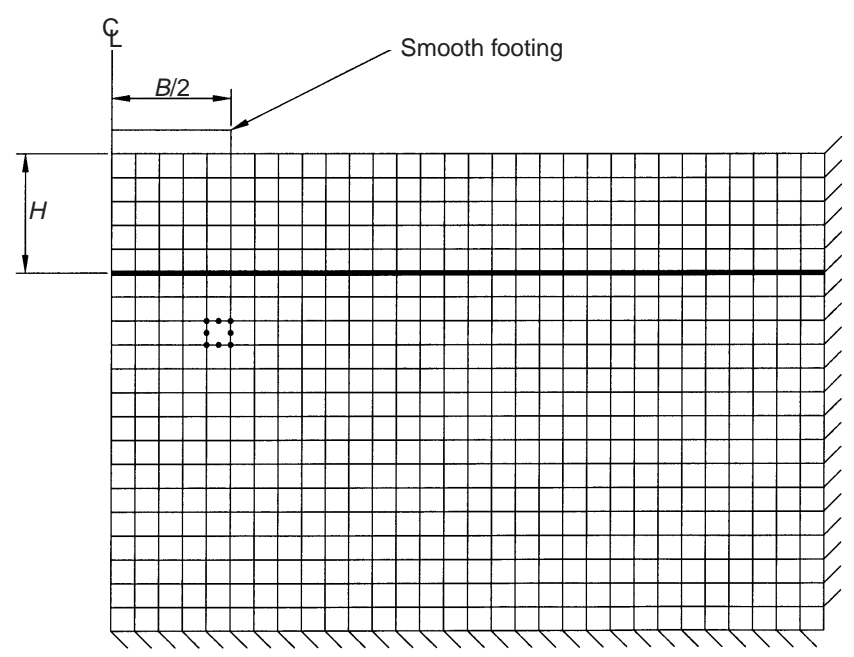

Fig. 19. Typical mesh used in displacement finite element analysis solutions to a range of collapse problems in geomechanics, especially plane strain analyses involving $\phi_{\mathrm{u}}=0$ soil. In the 1982 paper mentioned above, the two-layered clay bearing problem was solved quite successfully using a relatively crude finite element mesh.

To avoid any further misunderstanding on this issue, a more thorough parametric study of the two-layer problem has been performed using a version of Program 6.0 (8-node quadrilaterals, reduced integration) from the published software of Smith \& Griffiths (1988).

A typical mesh for this study is shown in Fig. 19. In all the analyses, a vertical displacement, $\delta_{\mathrm{v}}$, was applied incrementally to a smooth footing, with nodal reactions beneath the footing back-figured after each increment from the converged stress

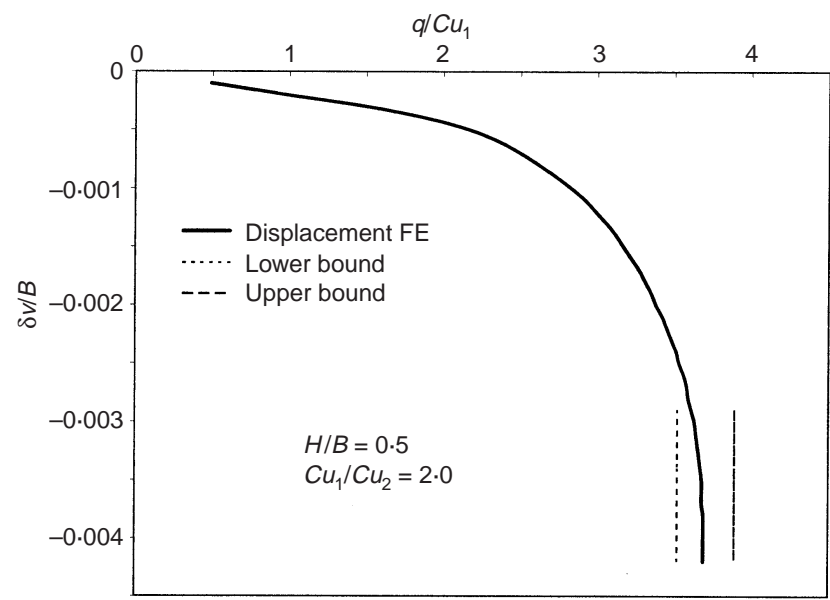

Fig. 20. Typical load-displacement curve from displacement finite element analysis

Table 4. Computed values of $N_{\mathrm{c}}^{*}$ and $\boldsymbol{F}_{\max }(H / B<1)$

\begin{tabular}{c|c|c|c|c|c}
\hline$H / B$ & $c_{\mathrm{u} 1} / c_{\mathrm{u} 2}$ & \multicolumn{3}{|c|}{ Bearing capacity factor, $N_{\mathrm{c}}^{*}$} & \multirow{2}{*}{$F_{\max }$} \\
\cline { 3 - 5 } & & Lower bound & Displacement FE & Upper bound & \\
\hline $0 \cdot 2$ & $0 \cdot 20$ & $5 \cdot 44$ & $5 \cdot 81$ & $5 \cdot 89$ & $0 \cdot 0254$ \\
& $0 \cdot 25$ & $5 \cdot 44$ & $5 \cdot 79$ & $5 \cdot 89$ & $0 \cdot 0201$ \\
& $0 \cdot 33$ & $5 \cdot 44$ & $5 \cdot 78$ & $5 \cdot 89$ & $0 \cdot 0154$ \\
& $0 \cdot 40$ & $5 \cdot 44$ & $5 \cdot 77$ & $5 \cdot 89$ & $0 \cdot 0118$ \\
& $0 \cdot 50$ & $5 \cdot 44$ & $5 \cdot 76$ & $5 \cdot 89$ & $0 \cdot 0076$ \\
& $0 \cdot 57$ & $5 \cdot 44$ & $5 \cdot 75$ & $5 \cdot 89$ & $0 \cdot 0062$ \\
& $0 \cdot 66$ & $5 \cdot 42$ & $5 \cdot 75$ & $5 \cdot 89$ & $0 \cdot 0052$ \\
& $0 \cdot 80$ & $5 \cdot 30$ & $5 \cdot 63$ & $5 \cdot 71$ & $0 \cdot 0031$ \\
& $1 \cdot 00$ & $4 \cdot 86$ & $5 \cdot 11$ & $5 \cdot 32$ & $0 \cdot 0014$ \\
& $1 \cdot 25$ & $4 \cdot 06$ & $4 \cdot 34$ & $4 \cdot 57$ & $0 \cdot 0024$ \\
& $1 \cdot 50$ & $3 \cdot 57$ & $3 \cdot 80$ & $4 \cdot 02$ & $0 \cdot 0017$ \\
& $1 \cdot 75$ & $3 \cdot 19$ & $3 \cdot 40$ & $3 \cdot 59$ & $0 \cdot 0018$ \\
& $2 \cdot 00$ & $2 \cdot 90$ & $3 \cdot 08$ & $3 \cdot 24$ & $0 \cdot 0015$ \\
& $2 \cdot 50$ & $2 \cdot 46$ & $2 \cdot 61$ & $2 \cdot 77$ & $0 \cdot 0012$ \\
& $3 \cdot 00$ & $2 \cdot 15$ & $2 \cdot 28$ & $2 \cdot 44$ & $0 \cdot 0008$ \\
& $3 \cdot 50$ & $1 \cdot 93$ & $2 \cdot 03$ & $2 \cdot 19$ & $0 \cdot 0006$ \\
& $4 \cdot 00$ & $1 \cdot 75$ & 1.82 & $2 \cdot 00$ & $0 \cdot 0006$ \\
& $5 \cdot 00$ & $1 \cdot 48$ & $1 \cdot 51$ & $1 \cdot 73$ & $0 \cdot 0006$
\end{tabular}


Table 4. (continued)

\begin{tabular}{c|c|c|c|c|c}
\hline$H / B$ & \multirow{2}{*}{$c_{\mathrm{u} 1} / c_{\mathrm{u} 2}$} & \multicolumn{3}{|c|}{ Bearing capacity factor, $N_{\mathrm{c}}^{*}$} & \multirow{2}{*}{$F_{\max }$} \\
\cline { 3 - 5 } & & Lower bound & Displacement FE & Upper bound \\
\hline \multirow{2}{*}{$0 \cdot 5$} & $0 \cdot 20$ & $4 \cdot 86$ & $5 \cdot 14$ & $5 \cdot 31$ & $0 \cdot 0110$ \\
& $0 \cdot 25$ & $4 \cdot 86$ & $5 \cdot 14$ & $5 \cdot 31$ & $0 \cdot 0093$ \\
& $0 \cdot 33$ & $4 \cdot 86$ & $5 \cdot 14$ & $5 \cdot 31$ & $0 \cdot 0070$ \\
& $0 \cdot 40$ & $4 \cdot 86$ & $5 \cdot 14$ & $5 \cdot 31$ & $0 \cdot 0059$ \\
& $0 \cdot 50$ & $4 \cdot 86$ & $5 \cdot 14$ & $5 \cdot 31$ & $0 \cdot 0040$ \\
& $0 \cdot 57$ & $4 \cdot 86$ & $5 \cdot 14$ & $5 \cdot 31$ & $0 \cdot 0034$ \\
& $0 \cdot 66$ & $4 \cdot 86$ & $5 \cdot 14$ & $5 \cdot 31$ & $0 \cdot 0029$ \\
& $0 \cdot 80$ & $4 \cdot 86$ & $5 \cdot 14$ & $5 \cdot 31$ & $0 \cdot 0021$ \\
& $1 \cdot 00$ & $4 \cdot 86$ & $5 \cdot 11$ & $5 \cdot 32$ & $0 \cdot 0015$ \\
& $1 \cdot 25$ & $4 \cdot 42$ & $4 \cdot 66$ & $4 \cdot 94$ & $0 \cdot 0019$ \\
& $1 \cdot 50$ & $4 \cdot 07$ & $4 \cdot 27$ & $4 \cdot 48$ & $0 \cdot 0024$ \\
& $1 \cdot 75$ & $3 \cdot 77$ & $3 \cdot 95$ & $4 \cdot 16$ & $0 \cdot 0024$ \\
& $2 \cdot 00$ & $3 \cdot 52$ & $3 \cdot 69$ & $3 \cdot 89$ & $0 \cdot 0019$ \\
& $2 \cdot 50$ & $3 \cdot 13$ & $3 \cdot 27$ & $3 \cdot 47$ & $0 \cdot 0017$ \\
& $3 \cdot 00$ & $2 \cdot 84$ & $2 \cdot 96$ & $3 \cdot 16$ & $0 \cdot 0015$ \\
& $3 \cdot 50$ & $2 \cdot 62$ & $2 \cdot 71$ & $2 \cdot 93$ & $0 \cdot 0013$ \\
& $4 \cdot 00$ & $2 \cdot 44$ & $2 \cdot 50$ & $2 \cdot 74$ & $0 \cdot 0011$ \\
& $5 \cdot 00$ & $2 \cdot 16$ & $2 \cdot 15$ & $2 \cdot 44$ & $0 \cdot 0008$ \\
\hline \multirow{6}{*}{} & & & &
\end{tabular}

field. Convergence after each increment was defined as having occurred when the nodal displacements from one iteration to the next were changing by less than $0 \cdot 1 \%$.

Bearing capacity failure was deemed to have occurred when the nodal reactions reached a maximum and levelled out to within a tolerance of $0 \cdot 1 \%$. A typical plot of the development of bearing resistance with vertical displacement is shown in Fig. 20.
The shear strength of each layer of undrained clay was governed by Tresca's failure criterion, defined by the dimensionless function

$$
F=\frac{\left(\sigma_{1}-\sigma_{3}\right)}{2 c_{\mathrm{u}}}-1
$$

Positive values of $F$ generated within the mesh were considered

Table 5. Computed values of $N_{\mathrm{c}}^{*}$ and $\boldsymbol{F}_{\max }(H / B>1)$

\begin{tabular}{c|c|c|c|c|c}
\hline$H / B$ & $c_{\mathrm{u} 1} / c_{\mathrm{u} 2}$ & \multicolumn{3}{|c|}{ Bearing capacity factor, $N_{\mathrm{c}}^{*}$} & \multirow{2}{*}{$F_{\max }$} \\
\cline { 3 - 5 } & & & & & \\
\hline \multirow{1}{*}{$1 \cdot 0$} & & Lower bound & Displacement FE & Upper bound & \\
& $0 \cdot 20$ & $4 \cdot 94$ & $5 \cdot 11$ & $5 \cdot 32$ & $0 \cdot 0074$ \\
& $0 \cdot 25$ & $4 \cdot 94$ & $5 \cdot 11$ & $5 \cdot 30$ & $0 \cdot 0058$ \\
& $0 \cdot 33$ & $4 \cdot 94$ & $5 \cdot 11$ & $5 \cdot 30$ & $0 \cdot 0044$ \\
& $0 \cdot 40$ & $4 \cdot 94$ & $5 \cdot 11$ & $5 \cdot 30$ & $0 \cdot 0037$ \\
& $0 \cdot 50$ & $4 \cdot 94$ & $5 \cdot 11$ & $5 \cdot 30$ & $0 \cdot 0026$ \\
& $0 \cdot 57$ & $4 \cdot 94$ & $5 \cdot 11$ & $5 \cdot 30$ & $0 \cdot 0023$ \\
& $0 \cdot 66$ & $4 \cdot 94$ & $5 \cdot 11$ & $5 \cdot 30$ & $0 \cdot 0020$ \\
& $0 \cdot 80$ & $4 \cdot 94$ & $5 \cdot 11$ & $5 \cdot 30$ & $0 \cdot 0016$ \\
& $1 \cdot 00$ & $4 \cdot 94$ & $5 \cdot 11$ & $5 \cdot 30$ & $0 \cdot 0014$ \\
& $1 \cdot 25$ & $4 \cdot 87$ & $5 \cdot 11$ & $5 \cdot 30$ & $0 \cdot 0011$ \\
& $1 \cdot 50$ & $4 \cdot 77$ & $4 \cdot 97$ & $5 \cdot 18$ & $0 \cdot 0010$ \\
& $1 \cdot 75$ & $4 \cdot 60$ & $4 \cdot 78$ & $5 \cdot 00$ & $0 \cdot 0009$ \\
& $2 \cdot 00$ & $4 \cdot 44$ & $4 \cdot 61$ & $4 \cdot 82$ & $0 \cdot 0010$ \\
& $2 \cdot 50$ & $4 \cdot 14$ & $4 \cdot 33$ & $4 \cdot 50$ & $0 \cdot 0010$ \\
& $3 \cdot 00$ & $3 \cdot 89$ & $4 \cdot 12$ & $4 \cdot 24$ & $0 \cdot 0007$ \\
& $3 \cdot 50$ & $3 \cdot 69$ & $3 \cdot 95$ & $4 \cdot 02$ & $0 \cdot 0006$ \\
& $4 \cdot 00$ & $3 \cdot 46$ & $3 \cdot 81$ & $3 \cdot 83$ & $0 \cdot 0006$ \\
& $5 \cdot 00$ & $3 \cdot 10$ & $3 \cdot 58$ & $3 \cdot 54$ & $0 \cdot 0005$ \\
\hline \multirow{1}{*}{$1 \cdot 5$} & $0 \cdot 20$ & $4 \cdot 94$ & $5 \cdot 11$ & $5 \cdot 30$ & $0 \cdot 0070$ \\
& $0 \cdot 25$ & $4 \cdot 94$ & $5 \cdot 11$ & $5 \cdot 30$ & $0 \cdot 0058$ \\
& $0 \cdot 33$ & $4 \cdot 94$ & $5 \cdot 11$ & $5 \cdot 30$ & $0 \cdot 0041$ \\
& $0 \cdot 40$ & $4 \cdot 94$ & $5 \cdot 11$ & $5 \cdot 30$ & $0 \cdot 0034$ \\
& $0 \cdot 50$ & $4 \cdot 94$ & $5 \cdot 11$ & $5 \cdot 30$ & $0 \cdot 0029$ \\
& $0 \cdot 57$ & $4 \cdot 94$ & $5 \cdot 11$ & $5 \cdot 30$ & $0 \cdot 0025$ \\
& $0 \cdot 66$ & $4 \cdot 94$ & $5 \cdot 11$ & $5 \cdot 30$ & $0 \cdot 0021$ \\
& $0 \cdot 80$ & $4 \cdot 94$ & $5 \cdot 11$ & $5 \cdot 30$ & $0 \cdot 0017$ \\
& $1 \cdot 00$ & $4 \cdot 94$ & $5 \cdot 11$ & $5 \cdot 32$ & $0 \cdot 0013$ \\
& $1 \cdot 25$ & $4 \cdot 87$ & $5 \cdot 11$ & $5 \cdot 27$ & $0 \cdot 0024$ \\
& $1 \cdot 50$ & $4 \cdot 87$ & $5 \cdot 11$ & $5 \cdot 31$ & $0 \cdot 0019$ \\
& $1 \cdot 75$ & $4 \cdot 87$ & $5 \cdot 11$ & $5 \cdot 31$ & $0 \cdot 0017$ \\
& $2 \cdot 00$ & $4 \cdot 87$ & $5 \cdot 11$ & $5 \cdot 31$ & $0 \cdot 0014$ \\
& $2 \cdot 50$ & $4 \cdot 84$ & $5 \cdot 07$ & $5 \cdot 32$ & $0 \cdot 0014$ \\
& $3 \cdot 00$ & $4 \cdot 69$ & $4 \cdot 94$ & $5 \cdot 15$ & $0 \cdot 0014$ \\
& $3 \cdot 50$ & $4 \cdot 46$ & $4 \cdot 79$ & $4 \cdot 98$ & $0 \cdot 0012$ \\
& $4 \cdot 00$ & $4 \cdot 24$ & $4 \cdot 69$ & $4 \cdot 84$ & $0 \cdot 0011$ \\
& $5 \cdot 00$ & $3 \cdot 89$ & $4 \cdot 50$ & $4 \cdot 56$ & $0 \cdot 0009$ \\
\hline
\end{tabular}


'illegal' and redistributed to neighbouring regions that still had reserves of strength.

Using the authors' definition of the bearing capacity factor

$$
N_{\mathrm{c}}^{*}=q_{\mathrm{u}} / c_{\mathrm{u} 1}
$$

computed values of this quantity by elasto-plastic displacement finite elements are shown in Tables 4 and 5 and Fig. 21, for a range of cases, together with $F_{\max }$, the maximum value of $F$ observed within the mesh at convergence. It should be noted that the limit solutions for $H / B=0.2$ were obtained by linear interpolation of results from the authors' paper.

The upper and lower bounds bracket the displacement finite element results, as might be expected, the one exception being when $H / B=1$ and $c_{\mathrm{u} 1} / c_{\mathrm{u} 2}=5$, where the upper bound solution appears to drift slightly below the displacement finite element result.

The reason for this discrepancy is unclear; however, the tables indicate consistently small values of $F_{\max }$, indicating a

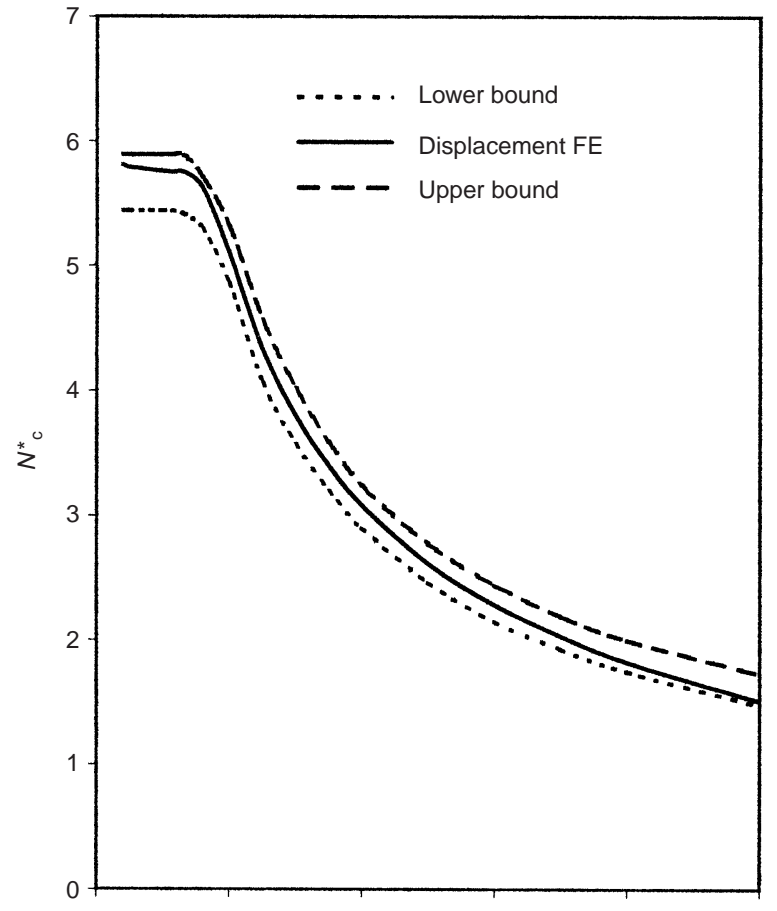

(a)

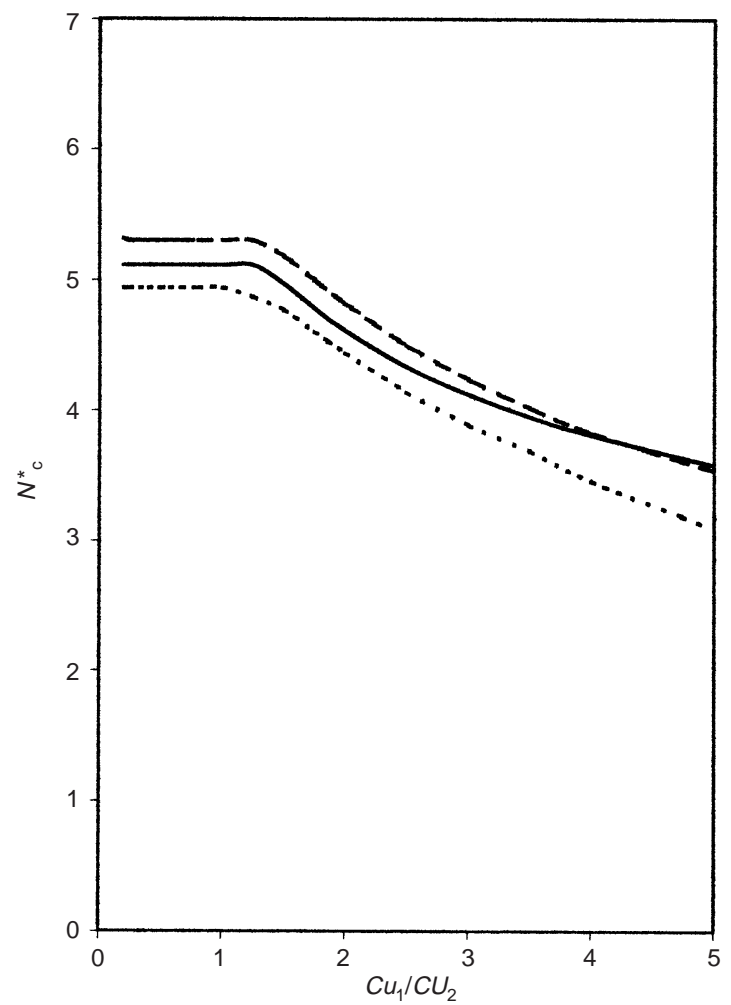

(c)

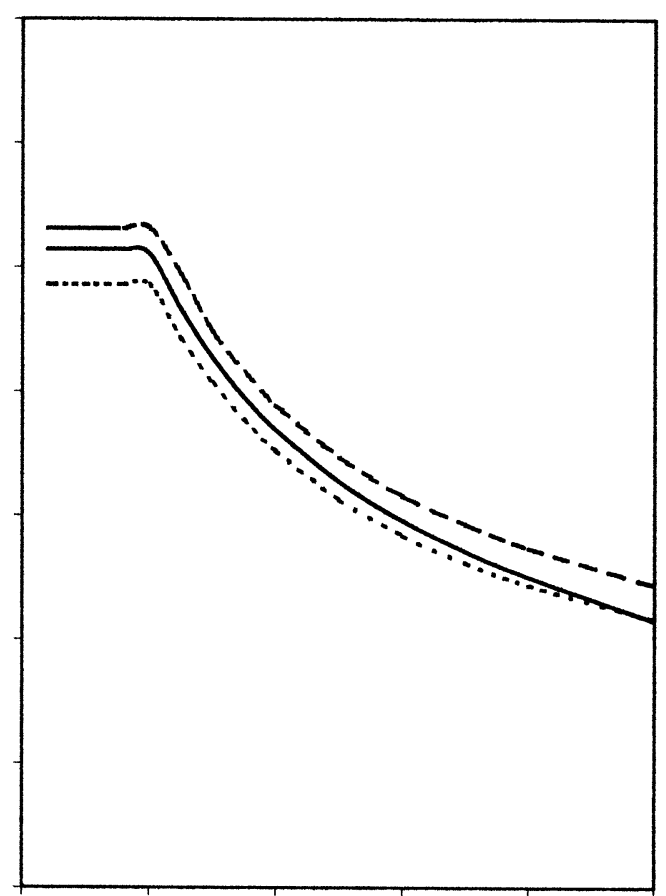

(b)

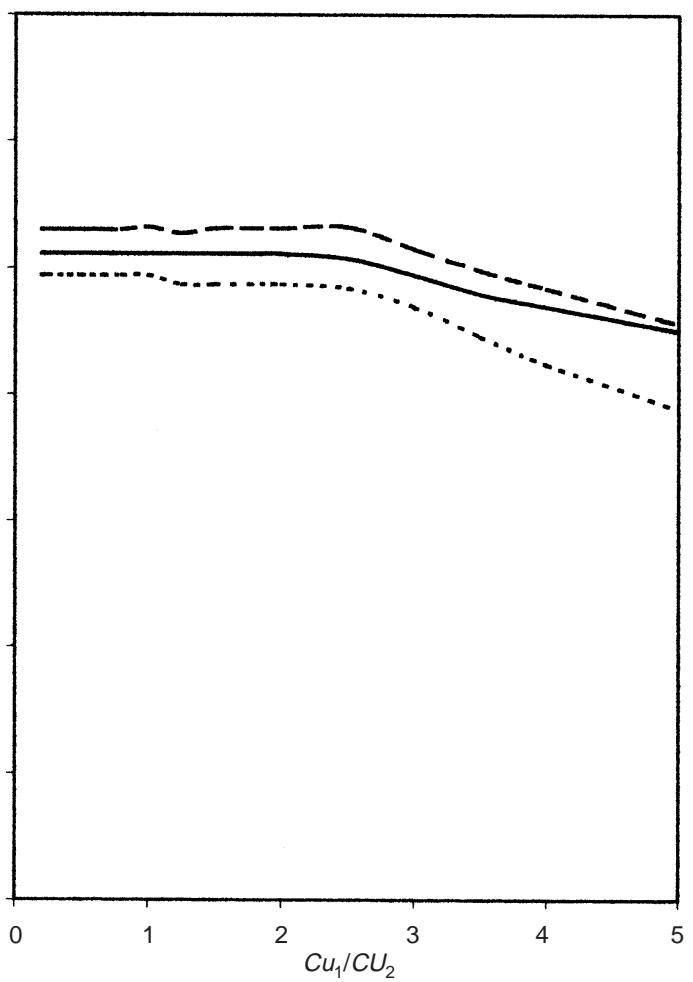

(d)

Fig. 21. Displacement elasto-plastic finite element solutions compared with upper and lower bounds: (a) $H / B=0 \cdot 2$; (b) $H / B=0.5 ;$ (c) $H / B=1.0 ;$ (d) $H / B=1.5$ 
high level of convergence and accuracy in the displacement finite element results.

Figure 22 shows typical nodal displacement patterns from the displacement finite element analyses at failure for the cases of 'weak on strong' and 'strong on weak'. The contrasting nature of the failure mechanisms in each case is clearly indicated.

In summary, elasto-plastic displacement finite element methods, in a single analysis, can be relied upon to give robust and accurate solutions to a wide range of geotechnical 'failure' problems.

\section{Authors' reply}

We should like to thank Goss and Griffiths for their interest in our paper. Their discussion does not focus on the results presented, but instead is chiefly concerned with the following statement: 'In practice, great care must be exercised when finite element analysis is employed to predict limit loads. Even for quite simple problems, experience has indicated that results from displacement finite element method tend to overestimate the true collapse load and, in some instances, fail to provide a clear indication of collapse altogether'.

It is a well-known fact that displacement finite element analysis of undrained geotechnical problems can encounter severe numerical difficulties. In particular, the accuracy of the stresses computed from conventional finite elements is often reduced dramatically as the compressibility approaches zero. This phenomenon, which leads to an erroneous stiffening of the load deformation response, is widely known as 'locking', and has been reported in the literature by many researchers (e.g. Herrmann, 1965; Christian, 1968; Zienkiewicz et al., 1971; Naylor, 1974; Nagtegaal et al., 1974; Sloan, 1981; Sloan \& Randolph, 1982; de Borst \& Vermeer, 1984; Burd \& Houlsby, 1990; Yu et al., 1993; Yu \& Netherton, 2000).

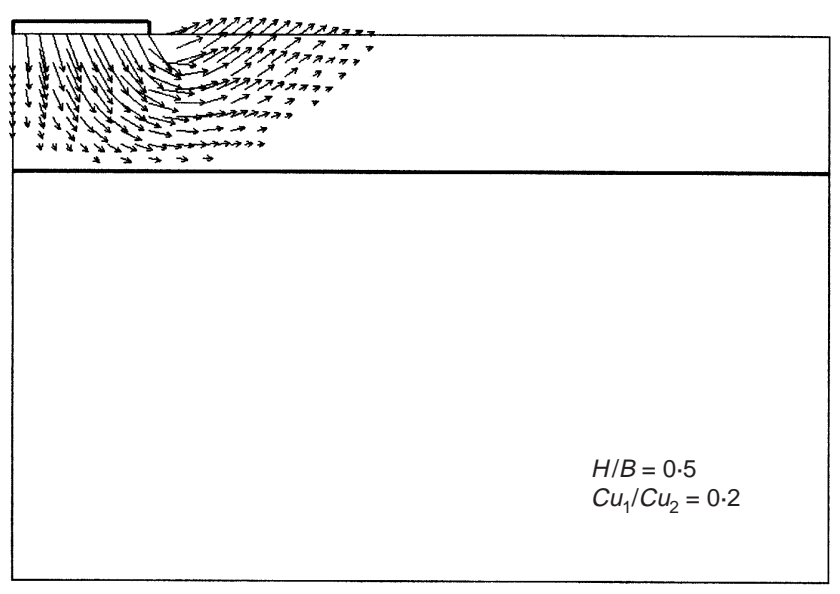

(a)

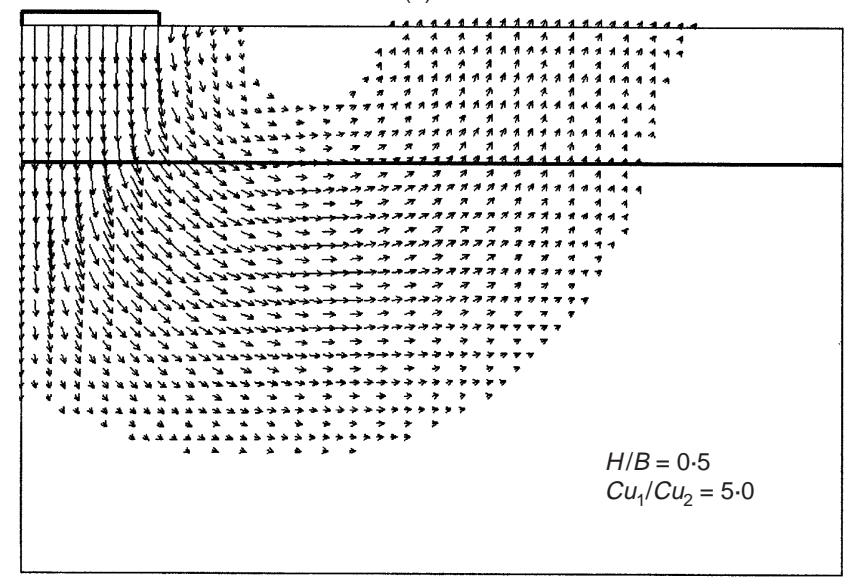

(b)

Fig. 22. Typical nodal displacement vectors at failure from displacement finite element analysis: (a) weak on strong; (b) strong on weak
In 1974, Nagtegaal et al. published a landmark paper on the difficulties associated with finite element calculations in the fully plastic range involving incompressible behaviour. By considering the limiting case of a very fine mesh, they proved that most displacement finite elements that employ low-order polynomials to model the displacement field are not suitable for incompressibility computations, particularly for axisymmetric problems. This is because the incremental incompressibility condition imposes a large number of constraints on the nodal velocities, which effectively reduces the available number of degrees of freedom. Since these constraints may multiply at a faster rate than the new degrees of freedom as the mesh is refined, it may not be possible to ensure that there are sufficient degrees of freedom available to accommodate the constant volume condition, regardless of how many elements are used in the grid.

One of the earlier approaches used to overcome this problem is the reduced integration rule suggested by Zienkiewicz et al. (1971). The element most commonly used in this method is the 8-noded rectangle with 4-point integration. As discussed by Naylor (1974) and Sloan \& Randolph (1982), reduced integration has the beneficial effect of decreasing the total number of incompressibility constraints on the nodal degrees of freedom. This is clearly seen by noting that the maximum number of constraints per element must be less than, or equal to, the total number of integration points used in the calculation of the element stiffness matrices. A quasi-theoretical justification for using reduced integration in analysing incompressible materials has been given by Malkus \& Hughes (1978). They proved that displacement formulations with reduced integration are, in certain cases, equivalent to mixed formulations where both stresses and displacements are treated as variables. Although conceptually appealing, this equivalence does not guarantee that spurious deformation modes will not occur.

Although it was once widely used in the finite element community, the reduced integration method can produce spurious stress and displacement oscillations. To illustrate the limitations of the reduced integration method, Sloan \& Randolph (1983) presented examples of footings and vertical cuts in which the reduced integration approach leads to incorrect or unacceptable deformation predictions. More recently, Naylor (1994) demonstrated that even a high-order element (cubic triangles), when used with six integration points (reduced integration), produces a zero-energy mechanism. These shortcomings are well known in the area of computational geomechanics and a number of other important cases have been discussed by Sloan (1981) and de Borst \& Vermeer (1984) among others. At a more fundamental level, the major limitation of using the reduced integration technique is that the incompressibility condition is satisfied only at a limited number of integration points, rather than everywhere within the element.

The authors did not mean to suggest that displacement finite elements should be avoided for collapse analysis, merely that they should be used with extreme care.

Finally, a major advantage of the methods used in the paper is that the upper and lower bounds automatically provide an error estimate for the limit loads. This feature is invaluable for collapse analysis where the exact solution is unknown.

\section{REFERENCES}

Burd, H. J. \& Houlsby, G. T. (1990). Finite element analysis of two cylindrical expansion problems involving near incompressible material behaviour. Int. J. Numer. Anal. Methods Geomech. 14, 351366.

Christian, J. T. (1968). Undrained stress distribution by numerical methods. J. Soil Mech. Found. Div., ASCE 96, 1289-1310.

de Borst, R. \& Vermeer, P. A. (1984). Possibilities and limitations of finite elements for limit analysis. Géotechnique 34, 199-210.

Griffiths, D. V. (1982). Computation of bearing capacity on layered soils. Proc. 4th Int. Conf. Numer. Methods Geomech. (ed. Z. Eisenstein), pp. 163-170. Rotterdam: Balkema. 
Griffiths, D. V. \& Lane, P. A. (1999). Slope stability analysis by finite elements. Géotechnique 49, No. 3, 387-403.

Herrmann, L. R. (1965). Elasticity equations for incompressible and nearly incompressible materials by a variational theorem. J. Am. Inst. Aeronautics and Astronautics 3, 1896-1900.

Malkus, D. S. \& Hughes, T. J. R. (1978). Mixed finite element methods-reduced and selective integration techniques: a unification of concepts. Comput. Methods Appl. Mech. Eng. 15, 63-81.

Nagtegaal, J. C., Parks, D. M. \& Rice, J. R. (1974). On numerically accurate finite element solutions in the fully plastic range. Comput. Methods Appl. Mech. Engng 4, 153-177.

Naylor, D. J. (1974). Stresses in nearly incompressible materials by finite elements with application to the calculation of excess pore pressures. Int. J. Numer. Methods Engng 8, 443-460.

Naylor, D. J. (1994). On integrating rules for triangles. In Numerical methods in geotechnical engineering (ed. Smith), pp. 111-114. Rotterdam: Balkema.

Smith, I. M. \& Griffiths, D. V. (1988). Programming the finite element method, 2nd edn. New York: John Wiley \& Sons.

Zienkiewicz, O. C., Humpheson, C. \& Lewis, R. W. (1975). Associated and non-associated viscoplasticity and plasticity in soil mechanics. Géotechnique 25, 671-689.

Sloan, S. W. (1981). 'Numerical analysis of incompressible and plastic solids using finite elements'. PhD Thesis, University of Cambridge, England.

Sloan, S. W. and Randolph, M. F. (1982). 'Numerical prediction of collapse loads using finite element methods'. Int. J. Num. Analy. Meth. Geomech. 6, 47-76.

Sloan, S. W. and Randolph, M. F. (1983). Discussion on 'Elasto-plastic analysis of deep foundations in cohesive soils' by D. V. Griffiths. Int. J. Num. Analy. Meth. Geomech. 7, 385-393.

Yu, H. S., Houlsby, G. T. and Burd, H. J. (1993). 'A novel isoparametric finite element displacement formulation for axisymmetric analysis of nearly incompressible materials'. Int. J. Num. Meth. Eng., 36, 2453-2472.

Yu, H. S. and Netherton, M. D. (2000). 'Performance of displacement finite elements for modelling incompressible materials'. Int. J. Num. Analy. Meth. Geomech. 24, 627-653.

Zienkiewicz, O. C., Taylor, R. L. and Too, T. M. (1971). 'Reduced integration technique in general analysis of plates and shells'. Int. J. Num. Meth. Eng., 3, 275-290. 